\section{Bariatric Surgery: Safe, Effective, and Unnecessary}

\section{TO THE EDITOR:}

Drs Varban and Dimick at the University of Michigan Department of Surgery provided a commentary in the July/August 2019 issue of Family Medicine: "Bariatric Surgery: Safe, Effective, and Underutilized."' They correctly describe the obesity epidemic in the United States and argue that current bariatric surgery methods are highly effective and relatively safe. If obesity were simply a disease that someone acquired like a virus, I would have no argument with them. However in the vast majority of patients, obesity is a lifestyleinduced disease triggered by our modern food environment and cultural norms. There is a better pathway out of obesity than surgery.

Maimonides admonished, "No disease that can be treated by diet should be treated any other means." Body fat mainly accumulates secondary to the excess consumption of carbohydrates, triggering repeated boluses of insulin resulting in insulin resistance, lipogenesis and blocking lipolysis. ${ }^{3-5}$ Dr Sarah Hallberg at Indiana University states that she is able to reverse obesity in a few months by having patients stop eating foods they do not need. ${ }^{6}$ There are essential fatty acids and essential amino acids, but there are no essential carbohydrates. The Inuit above the Arctic Circle and the Maasai and Samburu tribes of Africa do fine without carbohydrates. ${ }^{3}$ I am not arguing against eating any carbohydrates, but rather that we get them from real food such as vegetables and whole fruit. Refined carbohydrates in simple grains and sweets have a high glycemic index and glycemic load resulting in the insulin changes of obesity.
However, do not blame the victim. As pediatric endocrinologist at the University of California, San Francisco, Robert Lustig writes, in the name of profit, the American food industry has smothered the population with sugar and refined carbohydrates. ${ }^{7,8}$ Along with Sarah Hallberg at Indiana, Eric Westman, MD at Duke (former president of the American Bariatric Society), and Jason Fung, MD at the University of Toronto direct clinics that rapidly reverse morbid obesity using low carbohydrate nutrition, intermittent fasting, and other lifestyle approaches. ${ }^{3,9}$ This is the method that is underutilized in family medicine.

doi: 10.22454/FamMed.2020.281985

Joseph E. Scherger, MD, MPH

Eisenhower Health

Rancho Mirage, CA

\section{References}

1. Varban OA, Dimick JB. Bariatric Surgery: Safe, Effective, and Underutilized. Fam Med. 2019;51(7):552-554.

2. Maimonides. Brainyquote.com. 2019. https://www. brainyquote.com/quotes/maimonides_326756. Accessed October 29, 2019.

3. Fung J. The Obesity Code. Vancouver, BC: Greystone Books; 2016.

4. Ludwig DS, Friedman MI. Increasing adiposity: consequence or cause of overeating? JAMA. 2014;311(21):2167-2168.

5. Ludwig DS, Ebbeling CB. The Carbohydrate-Insulin Model of Obesity: Beyond “Calories In, Calories Out”. JAMA Intern Med. 2018;178(8):1098-1103.

6. Hallberg S. Reversing Type 2 diabetes starts with ignoring the guidelines [video]. YouTube. May 4, 2015. https://www. youtube.com/watch?v=da1vvigy5tQ\&vl=en. Accessed October 29, 2019.

7. Lustig RH. Fat Chance: Beating the Odds Against Sugar, Processed Foods, Obesity and Disease. New York: Penguin; 2013.

8. Lustig RH. The Hacking of the American Mind. New York: Penguin Random House; 2018.

9. Westman E. How to Reverse Diabetes. Get Better Wellness [Podcast]. 2016. http://getbetterwellness.com/?p=2524. Accessed October 29, 2019. 